\title{
An evaluation of the relation between food consumption rate and equilibrium body-weight in male rats
}

\author{
BY TOM W. GETTYS*, SUSAN MILLS AND DONALD M. HENRICKS $\dagger$ \\ Department of Animal Science, Clemson University, Clemson, SC 29634-0361, USA
}

\section{(Received 10 June 1987 - Accepted 11 March 1988)}

\begin{abstract}
1. Two experimental approaches were employed to assess the relation between food consumption rate and maintenance requirements in male weanling rats. The first approach involved restricting food intake in rats previously given free access to food from weaning to $59 \mathrm{~d}$ of age. The second approach involved restriction of food intake to various levels after weaning. Maintenance requirements ( $\mathrm{g}$ food/d per $\mathrm{g}$ body-weight $(\mathrm{W})$ ) were estimated by dividing the rate of food consumption by the resulting equilibrium W (EBW) for each animal. In addition, food consumption was partitioned into growth-independent (maintenance) and growth-dependent (gain) components by alternately setting $W$ and specific growth rate $\left(W^{\prime}\right)$ to zero in an equation relating food intake rate to $W$ and $W^{\prime}$. Coupling coefficients representing maintenance consumption ( $g$ food/d per $g$ W) and gain consumption ( $g$ food/g gain) were estimated for each animal by least squares.

2. Both techniques for estimating maintenance consumption provided similar estimates within and across experiments, and regardless of when food restriction was imposed or its severity, consumption for maintenance was about $5 \% \mathrm{~W} / \mathrm{d}$.

3. The EBW to which animals in each treatment group aspired was directly proportional to that group's food intake rate.

4. Coventional measures of growth efficiency were also related to food intake; efficiency decreased with decreasing food intake. Partitioning food consumption into maintenance and gain components revealed that as the rate of food intake decreased, the proportion of total intake consumed for maintenance increased. The results suggest that growth efficiency declines during food intake restriction because proportionately more of total intake is used for maintenance, leaving less available for gain.
\end{abstract}

Several recent reviews have addressed the subject of energy metabolism in mammals (Baldwin \& Bywater, 1984; Wiesser, 1984; Heusner, 1985; Blaxter, 1986), with special emphasis on the relation between body-weight (W) and basal metabolism. Various techniques, including determination of energy balance in serial slaughter experiments, and calorimetric estimation of fasting heat production, have been used to characterize this relation in several species (Brody, 1945; Lofgreen \& Garrett, 1968; Pullar \& Webster, 1977; Toutain et al. 1977; Blaxter \& Boyne, 1978). A common conclusion from these and other similar studies is that maintenance requirements are the product of a species-specific constant multiplied by $\mathrm{W}$ raised to some power less than 1 . Stated another way, this function guarantees that the maintenance requirement per unit body size declines as the animal grows to maturity.

An alternative and simpler concept of maintenance has been derived by studying the relation between equilibrium $W(\mathrm{EBW})$ resulting from constant fixed intakes of a defined diet. Parks (1982) reanalysed the data of Taylor \& Young $(1966,1967,1968)$ in cattle, Blaxter and co-workers (Clapperton \& Blaxter, 1965; Blaxter, 1968) in sheep, and Titus et al. (1934) in chickens, and found that the relation between EBW and food consumption was best defined as a straight line with zero intercept for all three species. Parks (1982) referred to the fitted line as the 'Taylor diagonal' since Taylor \& Young (1968) and Taylor et al. (1981) originally noted this relation in cattle and defined the slope of the fitted line as the efficiency of maintenance of EBW. At present, it is unclear whether the observed

* Present address : Division of Gastroenterology, Duke University School of Medicine, PO Box 3913, Durham, NC 27710, USA.

$\dagger$ For reprints. 
proportionality between maintenance requirements and $\mathrm{W}$ is a general phenomenon among species or whether alternative functions are necessary to describe the relation. Therefore, the purposes of the present study were to: (1) examine the relation between the EBW resulting from constant fixed intakes in male rats, and (2) compare the estimates of maintenance obtained from a model designed to partition food consumption into its simultaneous maintenance and gain components with maintenance requirements estimated from the EBW resulting from constant fixed intakes. A lesser objective was to relate conventional measures of food conversion efficiency to the estimated maintenance and gain coefficients.

\section{MATERIALS AND METHODS}

Two experiments were conducted to examine the relation between food consumption rate and EBW in male rats. Weanling Fischer F44 rats (Charles River, St Louis, Mo) were obtained from litters of approximately the same size (seven to ten pups) and housed individually in metabolism cages (Hazelton Systems Inc., Aberdeen, MD). The environmental temperature was maintained at $24^{\circ}$ with a $12 \mathrm{~h}$ light- $12 \mathrm{~h}$ dark regimen. Each rat was given a weighed amount of food daily (Lab Chow no. 5012; Ralston Purina, St Louis, Mo), and the unconsumed food was weighed the following day. Free access to water was provided. Rats were weighed at the outset of each experiment and every other day thereafter.

\section{Expt 1}

Fifteen weanling rats were individually housed and allowed free access to food from 23 to $59 \mathrm{~d}$ of age. Thereafter, five rats were randomly assigned to each of three groups: group 1 continued to be fed ad lib., group 2 received $60 \%$ of the chow provided to the ad lib. group, and group 3 received $50 \%$ of the chow provided to the ad lib. group. Actual food consumption and changes in $\mathrm{W}$ were tabulated as previously described. The experiment was terminated when the rats were $94 \mathrm{~d}$ of age.

\section{Expt 2}

Forty-four weanling rats were individually housed and eleven rats were randomly assigned to each of four groups: group 1 received $15 \mathrm{~g}$ chow/d (ad lib.), group 2 received $13.5 \mathrm{~g}$ chow/d ( $89 \%$ ad lib.), group 3 received $9.9 \mathrm{~g}$ chow/d (63\% ad lib.), and group 4 received $7.5 \mathrm{~g}$ chow $/ \mathrm{d}(49 \%$ ad lib.). The dietary regimen was imposed at $23 \mathrm{~d}$ of age and continued to $110 \mathrm{~d}$ of age. Actual food consumption and changes in $\mathrm{W}$ were monitored as previously described.

\section{Methods of analysis}

EBW was estimated for each animal in both experiments using functions appropriate to the shape of the response surface of $\mathrm{W}$ changes. The growth curves of animals increasing in size (ad lib. group in Expt 1 and all groups in Expt 2) were characterized with the asymmetric rising ogive given as

$$
\mathrm{W}=\frac{\gamma}{\left[1+\theta \mathrm{e}^{\sigma(\tau-x)}\right]^{1 / \theta}}
$$

where $\mathrm{W}$ is body-weight (g), $x$ is age (d), $\gamma$ is EBW (g), $\theta$ is a measure of relative positions of inflexion and half-growth points, $\sigma$ is standardized slope parameter, and $\tau$ is age at the inflexion point. The ogive was originally described by Verhultst (1838) and later by others for application in specific contexts (Lotka, 1924; Pearl, 1925; Gettys et al. 1986). The asymmetric ogive was adopted after testing for departure from the symmetric logistic pattern and imposing the condition $\delta=0$, where $\delta$ is the lower asymptote. Fitting the model given in Eqn (1) resulted in minimal departure from the original observations, as judged by 
comparing residual sums of squares from alternative models, and visual examination of the fitted curves. Parameter estimates, along with an estimate of their standard errors, were obtained using an iterative non-linear least squares routine in SAS (Statistical Analysis Systems, Cary, NC). EBW was estimated for animals in the two food-restricted groups of Expt 1 using the falling exponential given as

$$
\mathrm{W}=\alpha+\phi \mathrm{e}^{-\lambda(x-59)},
$$

where $\mathrm{W}$ is body-weight (g), $x$ is age (d), $\alpha$ is EBW (g), $\phi$ is $y$ intercept minus $\alpha$, and $\lambda$ is rate of decrease in W. Parameter estimates and accompanying standard errors were obtained as previously described.

Maintenance requirements for each rat in both experiments were estimated by two methods. The first method produced estimates referred to as calculated maintenance coefficents $\left(C \beta_{m}\right)$, and the estimates were obtained as

$$
C \beta_{m}=F_{c} / \mathrm{EBW},
$$

where $C \beta_{m}$ is $\mathrm{g}$ food consumed/d per $\mathrm{g} \mathrm{W}, F_{c}$ is asymptotic food consumption rate ( $\mathrm{g}$ food/ d), and EBW is equilibrium W. Maintenance coefficients were also estimated by a method which attempts to separate food consumption into its simultaneous maintenance and gain components (Gettys et al. 1987). The model is given as

$$
F(t)=E \beta_{m} \cdot \mathrm{W}(t)+\beta_{g} \cdot \mathrm{W}^{\prime}(t),
$$

where $F(t)$ is g food consumed/d at age $t, \mathrm{~W}(t)$ is body-weight at age $t, \mathrm{~W}^{\prime}(t)$ is rate of bodyweight gain at age $t, E \beta_{m}$ is estimated maintenance coefficient ( $\mathrm{g}$ food/d per $\mathrm{g} \mathrm{W}$ ), and $\beta_{g}$ is gain coefficient (g food/g gain). Eqn (4) is only applicable in animals gaining weight since it makes no provision for including the mobilization of internal energy reserves in the response variable $F(t)$. Thus, coefficients $E \beta_{m}$ and $\beta_{g}$ were estimated for the ad lib.-fed group in Expt 1 and all groups in Expt 2 by least squares. Estimates of the proportion of total intake consumed for gain were obtained for each animal in Expt 2 as the product of $\beta_{g}$ (gain coefficient; $\mathrm{g}$ food/g gain) and total weight gained. Estimates of the proportion of total intake consumed for maintenance were subsequently obtained as the difference between total food consumed and food consumed for gain. Conventional measures of food conversion (FCR) were obtained as the ratio, total food intake : total weight gained. Group differences among the growth attributes were examined by a one-way analysis of variance (Cochran \& Cox, 1957). The criterion used for detecting group effects was based on a level of protection agianst Type I errors set at $5 \%$.

The relation between EBW and constant rate of food intake was characterized by testing the adequacy of a straight-line formulation against curvilinear alternatives. All evidence was consistent with a straight line and zero intercept. The fitted line obtained by least squares was compared with the 'Taylor diagonal', defined by Parks (1982) as a straight-line relation between $\mathrm{W}$ and food consumption rate that has slope $A / C$, where $A$ is mature $\mathrm{W}$, and $C$ is the food consumption rate producing that value for $A$. A formal test of the hypothesis that the two lines are coincident is provided by the principle of conditional error applied to this alternative straight line. Imposition of the 'Taylor diagonal' on the original observations produces the conditional sum of squared residuals on $7 \mathrm{df}$, whereas the unconditional sum of squared residuals on $6 \mathrm{df}$ is obtained by fitting a straight line with zero intercept. The difference between conditional and unconditional sum of squared residuals is the sum of squares on $1 \mathrm{df}$, for the hypothesis of coincidence. The ratio of mean squares (hypothesis and error) is referred to upper percentage points $F_{1,6, \alpha}$ of the $F$-ratio distribution. 


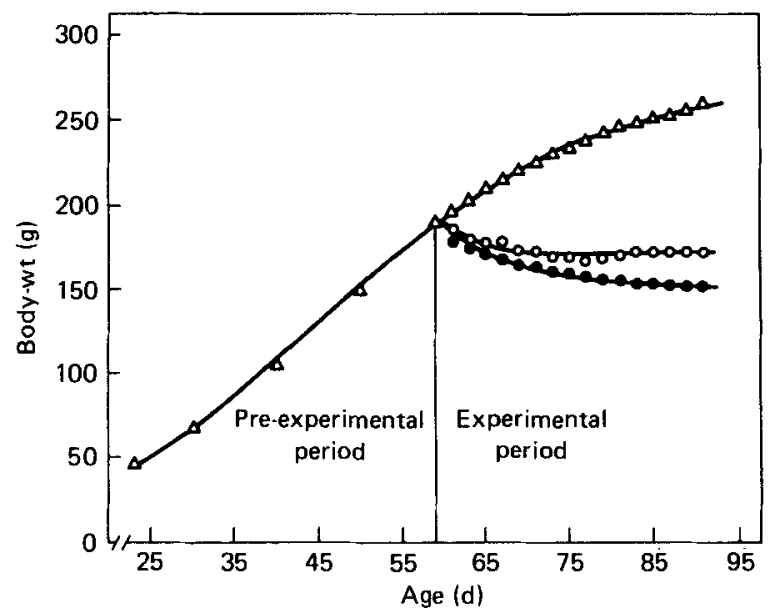

Fig. 1. The original observations and fitted curves depicting the relation between body-weight and age for the ad lib.-fed group $(\triangle), 60 \%$ ad lib.-fed group $(O)$, and the $50 \%$ ad lib.-fed group (O) for representative animals in each group. All animals were fed ad lib. during the pre-experimental period (weaning to $59 \mathrm{~d}$ ), and the original observations $(\triangle)$ during this period are the mean weights of all three representative rats. After $59 \mathrm{~d}$ of age, rats in each group were fed as indicated (see p. 152).

Table 1. Expt 1. Food consumption rates and maintenance coefficients estimated $\left(\mathrm{E} \beta_{\mathrm{m}}\right)$ and calculated $\left(\mathrm{C} \beta_{\mathrm{m}}\right)$ for rats aged 59-94 $d$

(Least squares means with their standard errors)

\begin{tabular}{|c|c|c|c|}
\hline $\begin{array}{l}\text { Dietary } \\
\text { group* }\end{array}$ & $\begin{array}{c}\text { Food } \\
\text { consumption } \\
\text { rate } \\
(\mathrm{g} \mathrm{food} / \mathrm{d})\end{array}$ & $\begin{array}{c}C \beta_{m}^{\dagger} \\
(\mathrm{g} \text { food } / \mathrm{d} \text { per } \mathrm{g} \mathrm{W})\end{array}$ & $\begin{array}{c}E \beta_{m} \ddagger \\
(\mathrm{g} \text { food } / \mathrm{d} \text { per } \mathrm{g} \mathrm{W})\end{array}$ \\
\hline Ad lib. & $14 \cdot 02$ & 0.0519 & 0.0585 \\
\hline $60 \%$ Ad lib. & $8 \cdot 21$ & 0.0502 & - \\
\hline $50 \%$ Ad lib. & 6.98 & 0.0494 & - \\
\hline SE & 0.22 & 0.0015 & 0.0018 \\
\hline
\end{tabular}

W, Body-weight.

* For details, see p. 152.

$\uparrow$ Obtained as the ratio, asymptotic food consumption rate:equilibrium W (Eqn (3) see p. 153).

$\ddagger$ Obtained in growing animals (ad lib. group) from Eqn (4) (p. 153).

Estimates not available in animals losing weight (60\% and $50 \%$ ad lib. groups).

\section{RESULTS}

\section{Expt 1}

The rate of food consumption for all animals increased from 23 to $30 \mathrm{~d}$ of age, and stabilized at a maximum of $14-15 \mathrm{~g} / \mathrm{d}$ by $35-40 \mathrm{~d}$ of age. Some day-to-day variation in food consumption rate was seen for all animals, but averaged over weekly intervals the consumption rate was constant after $35-40 \mathrm{~d}$ of age. The imposition of food restriction at $59 \mathrm{~d}$ of age led to immediate weight loss in the restricted groups (Fig. 1), and the rate of weight loss was related to the degree of food restriction (Fig. 1). Animals in group 1 continued to grow during the experimental period, but the rate of gain was declining (Fig. 1). The EBW to which animals in each group aspired were proportional to that group's level of food consumption.

Calculated maintenance coefficients $\left(C \beta_{m}\right)$ appeared to be unrelated to food consumption 

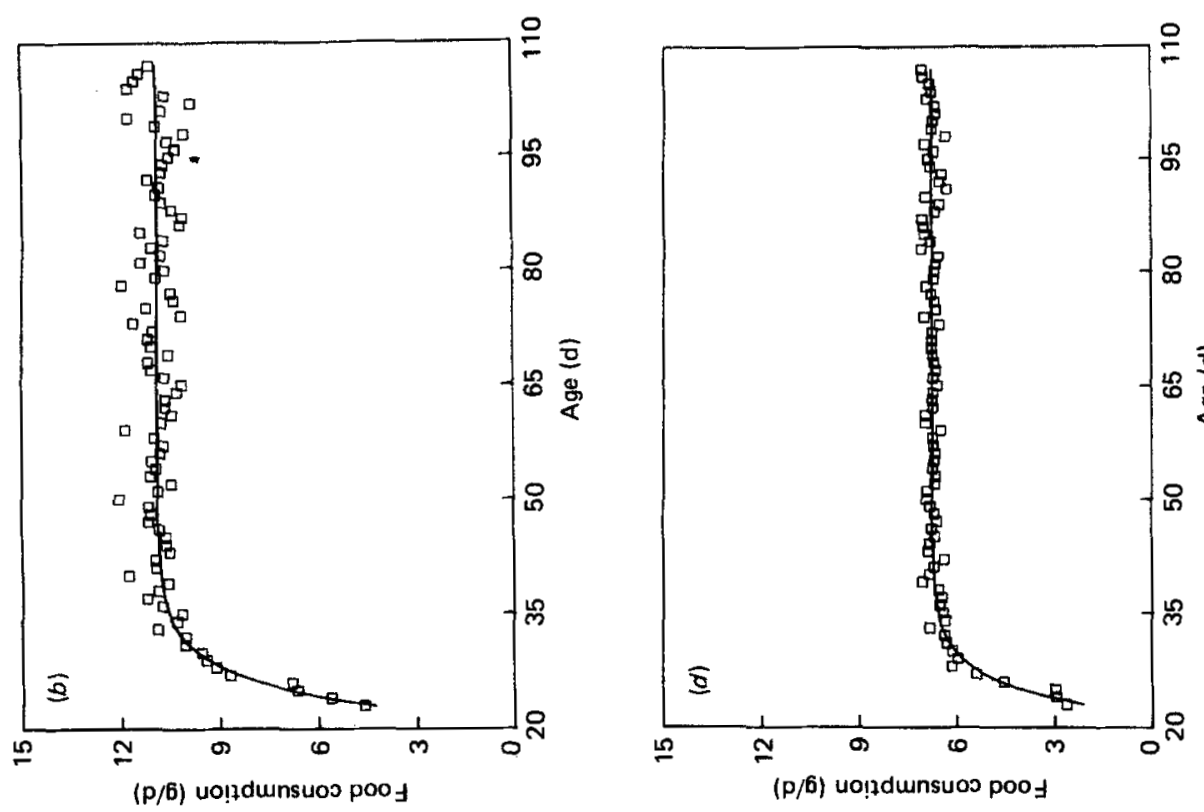

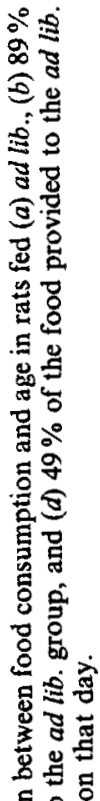

造兘
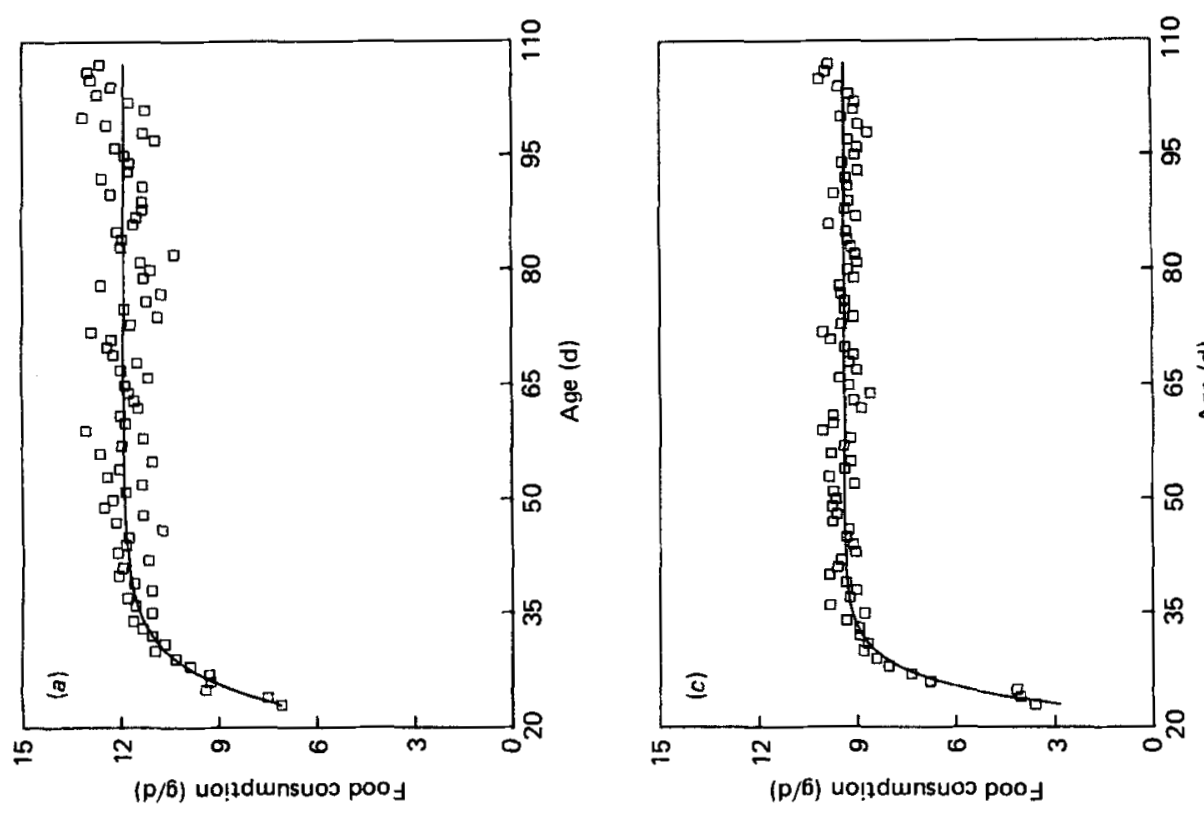

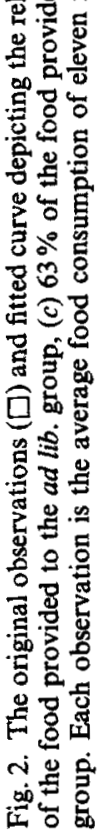


Table 2. Expt 2. Growth attributes from weaning to $110 \mathrm{~d}$ of age (Least squares means with their standard errors for eleven rats/group)

\begin{tabular}{lcccc}
\hline \hline $\begin{array}{l}\text { Dietary } \\
\text { group* }\end{array}$ & $\begin{array}{c}\text { Total food } \\
\text { consumption } \\
(\mathrm{g})\end{array}$ & $\begin{array}{c}\text { Total wt } \\
\text { gained } \\
(\mathrm{g})\end{array}$ & $\begin{array}{c}\text { Food conversion } \\
\text { ratio } \\
\text { (g food/g gain) }\end{array}$ & $\begin{array}{c}\text { Gain } \\
\text { coefficient } \\
\text { (g food/g gain) } \dagger\end{array}$ \\
\hline Ad lib. & 1048 & 190.8 & 5.49 & 1.150 \\
$89 \%$ Ad lib. & 940 & 162.3 & 5.79 & 1.142 \\
$66 \%$ Ad lib. & 823 & 134.5 & 6.12 & 1.000 \\
$49 \%$ Ad lib. & 647 & 86.8 & 7.45 & 0.953 \\
SE & 22 & 5.5 & 0.12 & 0.037 \\
\hline
\end{tabular}

* For details, see p. 152

† Estimated values obtained from Eqn (4) (see p. 153), representing the food consumption per unit gain after accounting for maintenance.

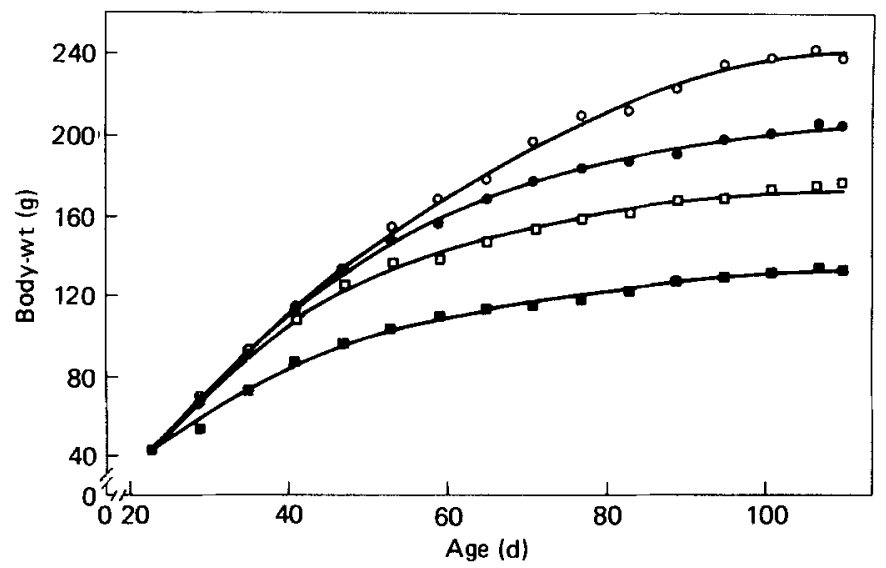

Fig. 3. The original observations and fitted curves depicting the relation between mean body-weight ( $n$ 11) and age for the ad lib.-fed group (O), $89 \%$ ad lib.-fed group (-), $66 \%$ ad lib.-fed group ( $\square$ ), and $49 \%$ ad lib.-fed group ( $\square$. The experiment began at weaning and animals were weighed every other day (see p. 152). For clarity, only body-weights at 6-d intervals are presented.

Table 3. Equilibrium body-weights ( $E B W$ ), food consumption rates, and maintenance coefficients estimated $\left(\mathrm{E} \beta_{\mathrm{m}}\right)$ and calculated $\left(\mathrm{C} \beta_{\mathrm{m}}\right)$

(Least squares means with their standard errors for eleven rats/group)

\begin{tabular}{|c|c|c|c|c|}
\hline $\begin{array}{l}\text { Dietary } \\
\text { group* }\end{array}$ & $\begin{array}{l}\mathrm{EBW}+ \\
\text { (g) }\end{array}$ & $\begin{array}{c}\text { Food } \\
\text { consumption } \\
\text { rate } \\
(\mathrm{g} \text { food } / \mathrm{d})\end{array}$ & $\begin{array}{c}E \beta_{m} \ddagger \\
(\mathrm{g} \text { food } / \mathrm{d} \text { per } \mathrm{g} \mathrm{W})\end{array}$ & $\begin{array}{c}C \beta_{m} \S \\
(\mathrm{g} \text { food } / \mathrm{d} \text { per } \mathrm{g} \mathrm{W})\end{array}$ \\
\hline Ad lib. & $236 \cdot 1$ & 11.91 & 0.0559 & 0.0504 \\
\hline $89 \%$ Ad lib. & $207 \cdot 5$ & $10 \cdot 86$ & 0.0558 & 0.0523 \\
\hline $66 \%$ Ad lib. & $179 \cdot 5$ & $9 \cdot 38$ & 0.0576 & 0.0522 \\
\hline $49 \%$ Ad lib. & $131 \cdot 8$ & $6 \cdot 74$ & 0.0583 & 0.0512 \\
\hline $\mathrm{SE}$ & $5 \cdot 4$ & $0 \cdot 28$ & 0.0007 & 0.0005 \\
\hline
\end{tabular}

W, body-weight.

* For details, see p. 152.

$\dagger$ Obtained as upper asymptote from Eqn (1) (see p. 152).

$\ddagger$ Obtained from Eqn (4) (see p. 153).

$\S$ Obtained as the ratio, asymptotic food consumption rate: EBW (Eqn (3), see p. 153). 
rates, since food restriction resulted in no change in consumption for maintenance (Table 1). Both methods of estimating maintenance consumption (Eqns (3) and (4)) provided similar measures for the ad lib.-fed group (Table 1), although estimates obtained from Eqn (3) were slightly lower.

\section{Expt 2}

The rate of food consumption in the ad lib.-fed group increased during the 1st week of the experiment and stabilized by $35-40 \mathrm{~d}$ of age. A constant food consumption rate was also attained during this time period in the three remaining groups, since the respective food restrictions took effect almost immediately. Substantial day-to-day variation in food consumption rates was observed among all treatment groups, but as food restriction became more severe, animals came closer to consuming all food provided each day (Fig. 2). Despite the daily variation, food consumption rates averaged over all animals in each group were nearly constant throughout the experiment (Fig. 2). Total food consumption during the experiment was stratified in accordance with the experimental objectives (Table 2). As expected, the total weight gained was also related to feeding level, but FCR differed among the groups (Table 2). The food consumed per unit gain was lowest in the ad lib.-fed group, and increased in relation to the severity of food restriction (Table 2). Thus, the apparent costs of growth increased as food restriction increased. Partitioning food consumption into its simultaneous maintenance and gain components with Eqn (4) provided estimates of the energy costs of growth, after accounting for maintenance, which suggest that food restriction did not decrease the efficiency of growth (Table 2). Quite the contrary; gain coefficients $\left(\beta_{g}\right)$ were lowest in the two most restricted groups, and slightly higher in the ad lib.- and $89 \%$ ad lib.-fed groups (Table 2).

The mean growth curves for each group are provided in Fig. 3, and illustrate that the EBW to which animals in each group aspired was proportional to their level of food intake (Table 3). Continuation of the experiment for additional time would have improved the precision of EBW estimates. However, computation of the percentage of mature $W$ attained at the experiment's termination revealed that all groups had completed greater than $90 \%$ of their growth. The restricted groups had completed an even larger percentage of their growth. Precision of EBW estimates among animals within the same treatment was good (Table 3) and standard errors attached to the EBW estimate for each animal were generally small. In accordance with Expt 1, the respective maintenance coefficients estimated by Eqns (3) and (4) were similar among the groups and unrelated to the level of food restriction. Also consistent with Expt 1 was the finding that maintenance coefficients estimated with Eqn (3) for all groups were consistently 7-10\% lower than comparable estimates obtained with Eqn (4). Nevertheless, the two methods appear to provide similar estimates of consumption for maintenance in the growing male rat.

The experimental objective of stratifying consumption rates among the groups was accomplished, but the actual percentages of ad lib. food consumption attained by the restricted groups were somewhat higher than intended. The $89 \%$ ad lib.-fed group actually consumed at $90 \%$ of the $a d$ lib. rate, the $66 \%$ ad lib.-fed group actually consumed at $79 \%$ of the $a d$ lib. rate, and the $49 \%$ ad lib.-fed group actually consumed at $62 \%$ of the ad lib. rate. Although the actual food restriction was not as severe as intended, changes in FCR, and the proportions of total intake consumed for maintenance and gain were observed. The relations among these three variables are presented in Fig. 4, and suggest an explanation for the observed increase in FCR as food intake was restricted. The proportion of total intake consumed for maintenance increased as food intake was restricted, leaving a smaller proportion of total intake available for growth (Fig. 4). The results suggest that growth efficiency is a function of food intake rate and $\mathrm{W}$ in relation to $A$ (mature $\mathrm{W}$ ).

The relation between EBW and constant rate of food intake was characterized by a 

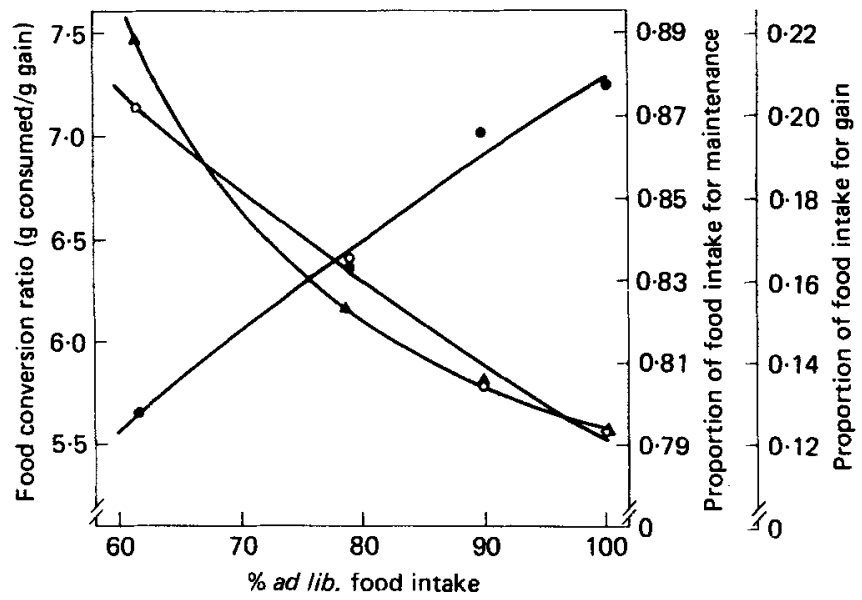

Fig. 4. The original observations and fitted curves depicting the relation between level of food intake and food conversion ratio $(\boldsymbol{A})$, between level of food intake and proportion of total intake consumed for maintenance $(\mathrm{O})$, and between level of food intake and proportion of total intake consumed for gain (O). Points are the mean of eleven observations, and the variables were calculated as described on $p$. 153.

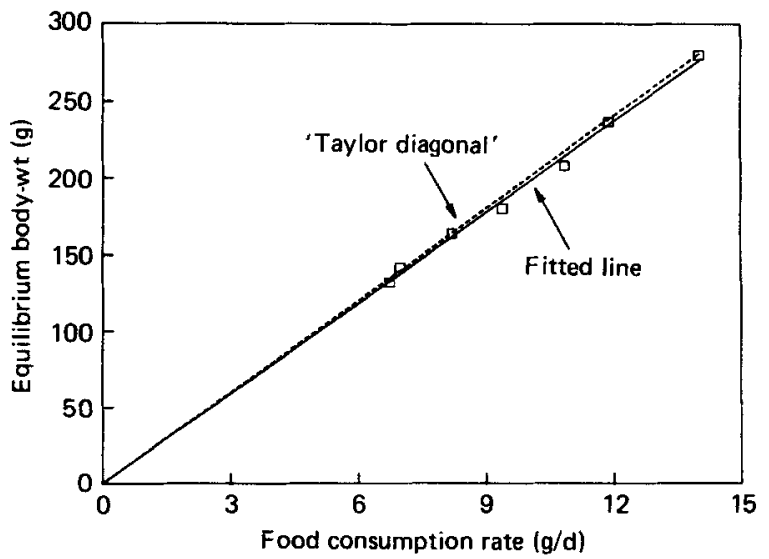

Fig. 5. The original observations $(\square)$ and fitted line depicting the relation between food consumption rate and equilibrium body-weight for all groups of rats in Expts 1 and 2. The theoretical relation referred to as the 'Taylor diagonal' (--) represents direct proportionality between food intake rate and equilibrium body-weight over the observed ranges for the two variables.

straight line with zero intercept. No evidence of curvilinearity was seen over the observed range of food intakes and $W$, regardless of whether EBW was approached by weight loss (Expt 1) or growth (Expt 2). The original observations from both experiments, the fitted line and 'Taylor diagonal' are presented in Fig. 5 and illustrate the proportionality of food consumption rates and the resulting EBW. Test of the hypothesis that the "Taylor diagonal' and fitted line were coincident failed to provide evidence that the two lines were different.

\section{DISCUSSION}

The rate of food intake stabilized shortly after weaning in the ad lib.-fed groups of both experiments, even though day-to-day variation in food intake was observed. Attainment of a constant rate of food consumption in the ad lib.-fed groups was important, particularly 
in Expt 2, since a constant food consumption rate was imposed on the remaining groups. Thus, conditions of similarity among all groups were realized with respect to the pattern of food consumption. The error associated with estimating $F_{c}$ (asymptotic food consumption rate) was smallest in the most restricted groups since they tended to be more thrifty with the food provided, and varied less from day-to-day in the amount of food consumed. Blaxter et al. (1982) noted stabilization of appetite shortly after weaning in sheep; the food consumption rate was characteristic of each animal and maintained over a fourfold change in W. Oscai \& McGarr (1978) noted stabilization of food consumption in rats slightly later in life than that reported here, and at levels which were slightly higher. Perhaps the diet offered in those studies was more palatable than the chow offered here. Examination of a compilation of results from nutrition experiments (Parks, 1982) revealed that attainment of a fairly constant food consumption rate is characteristic of several species. The importance of attainment of constant consumption is that it defines the nutrient resources available to the animal for subsequent growth to maturity. As noted by Blaxter (1986), relative to the body size when this consumption rate is reached, and the efficiency of its use for maintenance, $F_{c}$ defines the expected mature size and the trajectory of approach to it.

Our finding that the rate of food consumption was related to the apparent efficiency of growth was also observed by Oscai (1980) using a slightly different experimental design. In both instances, animals requiring a smaller proportion of total intake for maintenance grew more efficiently. An intuitive result of the interdependence of food consumption rates and body size in relation to mature size, is that growth efficiency is a function of them both. Care must be taken in experiments where conventional measures of growth efficiency are used as response variables to insure that changes in growth efficiency can be attributed properly to the treatments. The concept of compensatory gain would appear to be one such instance where caution is warranted, since as Oscai (1980) has demonstrated, growth efficiency is far superior in smaller than in larger rats when both are consuming the same amount of food.

Parks (1982) studied growth responses to constant food intake in several species and found that the function best defining the relation between EBW and the constant rate of food consumption producing it was a straight line with zero intercept. Parks (1982) referred to the fitted line as the 'Taylor diagonal' since it was the findings of Taylor (Taylor \& Young, 1966, 1967, 1968) which first suggested testing the general applicability of this relation. From the findings presented here, it appears that the diagonal relation between EBW and food consumption rate can be extended to the male rat. Of particular interest is the applicability of this relation whether rats approach EBW from a lower (growth) or higher weight (weight loss due to food restriction). The 'Taylor diagonal' implies that maintenance requirements are a constant function of $W$, not metabolic body size $\left(W^{0.75}\right)$, which guarantees that maintenance requirements per unit body size decline during growth. Mowrey \& Hershberger (1982) studied the relation between energy intake and maintenance of $W$ in lean and obese Zucker rats and found that maintenance requirements were as closely related to $\mathrm{W}$ as they were to $\mathrm{W}^{\mathbf{0} 75}$ for both phenotypes. Perhaps the discrepancy between proportionality to $\mathrm{W}$ and proportionality to $\mathrm{W}^{0 \cdot 75}$ is due to changes in the efficency of food utilization for maintenance. If so, the decline in efficiency would have to be proportional to the projected decline in maintenance requirements to explain the present results. Blaxter (1986) suggested that the relation between EBW and food consumption rates observed by Taylor \& Young $(1966,1967,1968)$ could have been the result of distorted body compositions produced by limiting food consumption. The present study is subject to a similar criticism, although it is unclear whether differences in body compositions are related to the observed proportionality between EBW and food consumption rates. 
Morgan (1981) used Eqn (4) to estimate maintenance coefficients $\left(\beta_{m}\right)$ and gain coefficients $\left(\beta_{g}\right)$ in male rats $\left(\beta_{m} 0.0617, \beta_{g} 1 \cdot 33\right)$ which were similar to those obtained with Eqn (4) in the present study. Calculated maintenance coefficients $\left(C \beta_{m}\right)$ obtained with Eqn (3) tended to be lower than comparable estimates from Eqn (4), but the reason for these differences is unclear. Additional experience with the two models is needed to determine whether there is a systematic component in the observed differences between the estimates. Estimates for cattle using Eqn (4) (Morgan, 1981; Gettys et al. 1987) were similar to direct estimates of maintenance obtained from the relation between constant fixed food intakes and the resulting EBW (Taylor et al. 1981). The use of Eqn (4) to estimate $E \beta_{m}$ in growing animals assumes that consumption for maintenance is proportional to $\mathrm{W}$ over the range of W studied. The results from the present study provide direct evidence that this assumption is reasonable for male rats. Based on a comparison of $E \beta_{m}$ estimated by Eqn (4) and direct calculations obtained with Eqn (3), it is concluded that precise, accurate estimates of food required for maintenance can be obtained in the growing male rat using the methods described herein.

Technical Contribution no. 2723 from the South Carolina Agricultural Experiment Station.

\section{REFERENCES}

Baldwin, R. L. \& Bywater, A. C. (1984). Annual Review of Nutrition 4, 101-114.

Blaxter, K. L. (1968). In Growth and Development of Mammals pp. 329-344 [G. A. Lodge and G. E. Lamming, editors]. London: Butterworths.

Blaxter, K. L. (1986). Journal of Animal Science 63, Suppl. 2, 1-10.

Blaxter, K. L. \& Boyne, A. W. (1978). Journal of Agricultural Science, Cambridge 90, 47-68.

Blaxter, K. L., Fowler, V. R. \& Gill, J. C. (1982). Journal of Agricultural Science, Cambridge 98, $405-420$.

Brody, S. (1945). Bioenergetics and Growth. New York: Reinhold Publishing Co.

Clapperton, J. L. \& Blaxter, K. L. (1965). Proceedings of the Nutrition Society 24, xxxiii-xxxiv.

Cochran, W. G. \& Cox, G. M. (1957). Experimental Designs. New York: John Wiley and Sons.

Gettys, T. W., Burrows, P. M. \& Henricks, D. M. (1986). American Journal of Physiology 251, E357-E361.

Gettys, T. W., Henricks, D. M., Burrows, P. M. \& Schanbacher, B. D. (1987) Animal Production 44, $209-217$.

Heusner, A. A. (1985). Annual Review of Nutrition 5, 267-293.

Lofgreen, G. P. \& Garrett, W. N. (1968). Journal of Animal Science 27, 793-806.

Lotka, A. J. (1924). Elements of Physical Biology. Baltimore: William \& Wilkins (see Lotka, A. J. (1956). Elements of Mathematical Biology, 2nd ed. New York: Dover Publications).

Morgan, P. H. (1981). Nutrition Reviews 39, 321-327.

Mowrey, R. A. \& Hershberger, T. V. (1982). Journal of Nutrition 112, 2116-2121.

Oscai, L. B. (1980). American Journal of Physiology 238, E318-E321.

Oscai, L. B. \& McGarr, J. A. (1978). American Journal of Physiology 235, R141-R144.

Parks, J. R. (1982). A Theory of Feeding and Growth of Animals, pp. 83-108 [D. F. R. Bommer, B. R. Sabey, G. W. Thomas, Y. Vaadia and L. D. Van Vleck, editors]. Berlin, Heidelberg and New York: Springer Verlag.

Pearl, R. (1925). The Biology of Population Growth. New York: Knopf.

Pullar, J. D. \& Webster, A. J. F. (1977). British Journal of Nutrition 37, 355-363.

Taylor, St C. S., Turner, H. G. \& Young, G. B. (1981). Animal Production 33, 179-194.

Taylor, St C. S. \& Young, G. B. (1966). Journal of Agricultural Science, Cambridge 66, 67-85.

Taylor, St C. S. \& Young, G. B. (1967). Animal Production 9, 295-311.

Taylor, St. C. S. \& Young, G. B. (1968). Animal Production 10, 393-412.

Titus, H. W., Jull, M. A. \& Hendricks, W. A. (1934). Journal of Agricultural Science, Cambridge 48, 817-835.

Toutain, P. L., Toutain, C., Webster, A. J. F. \& McDonald, J. D. (1977). British Journal of Nutrition 38, $445-454$.

Verhultst, P. F. (1838). Correspondence in Mathematics and Physics 10, 113-121.

Wiesser, W. (1984). Respiratory Physiology 55, $1-9$. 